\title{
BP's Reputation Repair Strategies during the Gulf Oil Spill
}

\author{
Kristen Alley Swain \\ Meek School of Journalism and New Media, University of Mississippi, Box 1848, University, MS 38677, USA \\ Lindsay A. Jordan \\ Profiles Incorporated, 3000 Chestnut Avenue, Suite 201, Baltimore, MD 21211, USA \\ E-mail: lajordan13@gmail.com
}

Received 9 September 2014

Accepted 15 January 2015

\begin{abstract}
On April 20, 2010, British Petroleum's Deepwater Horizon drilling rig in the Gulf of Mexico exploded, creating the largest oil spill in U.S. history. Analysis of 1,161 BP tweets during the crisis response reflected unexpected reputation repair strategies and responsibility attribution. Situational Crisis Communication Theory suggests that after an accident, PR messages typically reflect low responsibility attribution. Although the official investigation initially did not suggest a preventable crisis, $90 \%$ of BP's tweets reflected high responsibility.
\end{abstract}

Keywords: reputation repair, responsibility attribution, oil spill, situational crisis communication theory

\section{Introduction}

On April 20, 2010, British Petroleum's Deepwater Horizon drilling rig located in the Gulf of Mexico ignited and exploded, leaving 11 members of its 126member crew missing and spewing thousands of gallons of oil into the Gulf. Transocean, the world's largest offshore drilling contractor, had been drilling an exploration well using the Deepwater Horizon as a contractor to BP. Transocean's Emergency and Family Response Team, BP, and the U.S. Coast Guard immediately began searching for the missing people, but suspended the search after covering 5,000 square miles. The 11 workers were pronounced dead, and their bodies were never recovered.

On April 22, BP CEO and British native Tony Hayward said, "We are determined to do everything in our power to contain the oil spill and resolve the situation as rapidly, safely, and effectively as possible." The Macondo well, from which the Deepwater Horizon was drilling for oil, would not be declared "dead" for nearly five months.

When the Deepwater Horizon rig sank, BP executed a major oil spill response. Initial response efforts included the implementation of a small fleet of response vessels, relief well planning, skimming of oily surface water, a protective boom to prevent oil from reaching the shoreline, and chemical dispersants to break up the oil, in an attempt to keep it from destroying marshes, mangroves, and beaches. Efforts to seal the well began as early as April 25, but many were unsuccessful. In early May, the drilling of a relief well and a back-up relief well began.

A Riser Insertion Tube Tool (RITT), which attempts to bring oil flow to the surface by inserting a tube into the broken end of the Deepwater Horizon's riser, and a Lower Marine Riser Package (LMRP) containment cap were also used to collect oil and pump it to the surface. A sealing cap was put in place on July 5 , and oil no longer flowed freely from the well. By 
Aug. 4, the U.S. government reported that three-fourths of the 4.9 million barrels of spilled oil had been evaporated, burned, skimmed, recovered, or dispersed. On Sept. 16, the relief well drilled by Development Driller III successfully intercepted the annulus of the Macondo well. The void in the leaking valve on the Deepwater Horizon was sealed. Finally, on Sept. 19, the U.S. federal government declared the well "effectively dead."

Monetary reimbursement efforts began shortly after the explosion with the initiation of a claims process, the opening of several claims offices, and the activation of a toll-free call center. BP's claims process followed the "responsible party" guidelines of the Oil Pollution Act of 1990, as the U.S. Coast Guard designated BP as a responsible party. From the time of the explosion to that of the interception by the relief well, BP paid out billions of dollars for statewide oil spill contingency plans, protection plans, research of the oil spill's effect on the environment and public health, tourism promotion for affected states, restoration of wildlife habitats, unemployed rig workers, the construction of barrier islands, personal claims, etc. BP claims to have spent more than $\$ 13$ billion on the cleanup, $\$ 500$ million on scientific studies, and $\$ 280$ million on wildlife rescue and rehabilitation.

\section{Background}

While BP was waging war against the oil in the Gulf, a war waged against its reputation. Not only did BP have to fix the largest oil spill in the history of the U.S., it also had to fix its damaged reputation. On the image front, BP had much to defend. BP spent heavily to position itself as an environmentally friendly company, redesigning its logo into a green-and-yellow sunburst and advertising its \$4-billion-alternative-energy push to move beyond petroleum (M. DeBord, 2010).

In BP's post-crisis phase of crisis communications, many experts debated the effectiveness of BP's PR campaign that accompanied the Gulf oil spill. After one year, and a PR bill of more than $\$ 90$ million, BP's reputation was still in question. BP's biggest PR mistake was lying to the public and regulators about its level of unpreparedness in combating a spill of such catastrophic proportions (J. Vidal, 2011). Some argued that BP's PR campaign will serve as a "how not to" case study for future crises (R. Blake, 2010).
Many of BP's so-called oil spill related PR blunders can be traced back to Tony Hayward, the company's then Chief Executive Officer (Associated Press, 2010). Although traditional crisis public relations campaigns suggest appointing one person, usually a company's $\mathrm{CEO}$, as the general spokesperson, British-born Hayward may not have been BP's best choice for an American tragedy. Some experts have suggested that BP's biggest mistake was its decision to have Hayward serve as the most prominent spokesperson on the oil spill (E. Reguly, 2010), as his lack of experience with U.S. culture was highlighted.

Although Hayward got points for making his way to the Gulf shortly after the explosion, people wanted to see him making an effort to fix the problem. Daniel Keeney, president of a Dallas-based PR firm said, "You want to get him right in the thick of things, even if he looks somewhat uncomfortable doing it"(E. McClam \& H. Weber, 2010).

On June 1, 2010, National Incident Commander Admiral Thad Allen was announced as a spokesperson separate from BP. The public was excited to learn of Allen's new position. "Allen was the reassuring spokesperson, the steady hand that the public needed to see. He consistently refused to put numbers on the flow rate or predict the final plugging of the Macondo" (D. Lenci \& J. Mullane, 2010). However, having Allen serve as a spokesperson further confused BP's public relations tactics since Allen was represented an entity separate from BP.

One basic rule of PR is to avoid finger pointing, as it can diminish a company's level of trustworthiness. Unfortunately, that is exactly what Hayward did during the immediate days following the explosion. He declared that the incident was "not our accident" (A. Brownsell, 2010); "What the hell did we do to deserve this?"; and "The Gulf of Mexico is a very big ocean. The amount of volume of oil and dispersant we are putting into it is tiny in relation to the total water volume" (B. Snyder, 2010).

Fraser Seitel, a communication consultant who writes for Jack O'Dwyer's PR Newsletter, claims that BP should not have made early predictions about the amount of oil involved in the spill, as it weakened the company's credibility (A. Caruba, 2010). U.S. Coast Guard Rear Admiral and Deputy On-Scene Commander Mary Landry initially said no oil was leaking from the Macondo well. Landry's estimates 
on leaking oil during the initial days of the spill rapidly increased from seepage, to 1,000 barrels per day, to 5,000 barrels per day, to 20,000 barrels per day, and finally to 100,000 barrels per day (D. Lenci, Denise \& J. Mullane, 2010).

\subsection{Use of social media as a crisis communication tool}

Along with executing elements of a traditional PR campaign (i.e. press releases, press conferences, etc.), BP also launched an extensive social media campaign. However, the success of this social media campaign continues to be disputed by social media experts ( $T$. Bergin, 2010). Prior to the oil spill in the Gulf, BP did have a Facebook page, a Twitter feed, and a LinkedIn account, but none were updated regularly. In the wake of the oil spill, a full week passed before BP initiated any sort of social media response. For example, @BP_America, BP's Twitter account, did not tweet about the oil spill until April 27, a full seven days after the spill.

In comparing the communications tactics pertaining to the Deepwater Horizon spill with that of the 1989 Exxon Valdez spill, Harlan Loeb, director of crisis and issues management at Edelman, a leading global PR firm, said that nowadays companies operate in a "24/7 risk environment" (A. Symington, 2010). According to Loeb, two key factors behind this change were the emergence of social media and nongovernmental organizations' increase in influence. Loeb also argues that social media offers companies "an extraordinary opportunity to break through the static of information flow to tell your own story" (A. Symington, 2010).

With the help of Oglivy Public Relations Worldwide and Purple Strategies, BP launched an aggressive social media campaign after the first few weeks following the explosion. The company added a "Gulf of Mexico response" page to its corporate website providing information on all aspects of the spill; began updating its Facebook page and Twitter feed on a daily and then hourly basis; and broadcasted videos on its YouTube channel and uploaded pictures to its Flickr account of response and recovery effort (B. Morrissey, 2010). BP also disabled comments from users who posted negative comments (A. Seitz-Wald, 2010).

\subsection{Twitter}

BP had a Twitter account prior to the Deepwater Horizon oil spill but failed to update the feed regularly. Following the spill, BP repurposed its account, @ $\mathrm{BP}$ America, to serve as a communication hub for updates and breaking news pertaining to the spill. However, it took BP several days to make this happen. In fact, BP did not tweet about the spill until April 27, seven days after the explosion. This tweet read, "BP PLEDGES FULL SUPPORT FOR DEEPWATER HORIZON PROBES." In 2010, BP's Twitter profile read: "Updates of BP's ongoing response efforts are provided by our own social media team, as well as onthe-ground personnel working in affected Gulf regions. From time to time, Mike Utsler, $\mathrm{COO}$ of BP's Gulf Coast Restoration, will be giving first-hand updates via this channel."

From its first oil spill tweet on April 27, BP's tweets gradually increased to multiple tweets per day. As of September 2014,@BP_America had 95,000 followers. More than a year after the incident,@BP_America currently reads, "Official account of BP America. Stay current on our commitment to the Gulf and our work toward secure, affordable energy while addressing climate change."

While BP was busy repurposing its Twitter account, a spoof account, @BPGlobalPR, was quickly gaining followers. As of September 2014, it had 132,000 followers, 28\% more than the official BP account. BP Public Relation's (@BPGlobalPR) profile reads, “This page exists to get BP's message and mission statement out into the twitterverse." This Twitter feed was quite detrimental to BP's Twitter efforts, publishing satirical tweets, such as, "Yes, we disabled the alarms on the Deepwater Horizon. Oh, like you've never hit the snooze button?" (B. Hatton, 2010). Miles Nadal, the chief executive of advertising conglomerate MDC Partners Inc., said, "The brand detractor is more influential and more vehement than the than the brand evangelist" (H. Shaw, 2010). This fact was quite unfortunate for BP's social media campaign.

\subsection{Crisis communication theory}

A crisis is defined as "a major occurrence with a potentially negative outcome affecting the organization, company, or industry, as well as its publics, products, services or good name" (K. Fearn-Banks, 2002). A crisis can present itself in many forms, and it will

Published by Atlantis Press

Copyright: the authors 
almost always disturb normal business activities. Depending on the severity of the crisis, it may even threaten the entire existence of the company or organization. Common types of crises include chemical spills or leaks, contamination, earthquakes, fires, hurricanes, product failures, and terrorism.

In order to successfully manage and overcome a crisis, companies must have a specific crisis management plan. Crisis management is the process of strategic planning for a crisis or negative turning point. It seeks to removes risk and uncertainty from the negative occurrence, so the organization can be in greater control of its own identity. Crisis management is the dialogue between the organization and its public prior to, during, and after the negative occurrence. These communications tactics are specifically designed to minimize damage to the image of the organization (K. Fearn-Banks, 2002).

There are three phases of crisis management: precrisis, crisis response, and post crisis. The pre-crisis phase focuses on crisis prevention and preparation. The crisis response phase focuses on successfully responding to an occurring crisis. The post-crisis phase focuses on preparing for future crises while fulfilling promises made during the actual crisis. Pre-crisis best practices include having a continually updated crisis management plan, having a designated and properly trained crisis management team, implementing mock crisis exercises to test the reliability of the plan, and pre-drafting messages to combat specific crises.

Post-crisis best practices include delivering promised information to stakeholders, continually updating stakeholders on the progress of the crisis recovery efforts, and closely reviewing the crisis management actions to see if they should be integrated into future crisis management plans. When a crisis does occur, the crisis response consists of what management does and says after the crisis hits in terms of its initial crisis response and its reputation repair and behavioral intentions. Initial crisis response best practices include giving a response to the crisis within the first hour, being accurate with facts, keeping the spokesperson(s) informed of key messages; focusing on public safety, successfully implementing the use of all available communication mediums, providing a human element be expressing concern and/or sympathy ( $\mathrm{T}$. Coombs, 2007).
During this phase, an organization's management is required to communicate important information to affected and/or interested audiences, and the public relations practitioner is responsible for shaping these messages. Most practitioners advise management to abide by three rules during the initial crisis response phase: be quick, be accurate, and be consistent. Of these three rules, a quick response is the most vital. In today's world of 24/7 digital media, people expect an immediate response, and this is exactly what an organization should give them. Even if the organization does not have an answer, an immediate response could simply state that the organization is in the process of gathering important information. "An early response may not have much 'new' information, but the organization positions itself as a source and begins to present its side of the story." (T. Coombs, 2007, p.2). The following list breaks down the best practices of the initial crisis response:

(i) Release an initial response as quickly as possible, preferably within the first hour following the crisis.

(ii) Be as accurate as possible by checking all facts and quickly correcting misinformation.

(iii) Make sure that the spokesperson(s) is consistent by having the public relations practitioner keep him or her updated with all information pertaining to crisis events and key messages.

(iv)Designate public safety as the crisis communications plan's top priority.

(v)Get key messages out by using all available communication channels. This include, but are not limited to, newspapers, radio, television, the organization's website, and social media outlets (T. Coombs, 2007).

\subsection{Evolution of crisis communications}

In the early hours of Friday, March 24, 1989, one of the most infamous crises in American history began to unfold. The 987-foot Exxon Valdez oil tanker was en route off the coast of Alaska to Sound to Long Beach, California, when it struck the Bligh Reef and began spewing 11 million gallons of crude oil into the waters of Prince William Sound. The largest oil spill in U.S. history, it killed an estimated two million sea animals. People gradually learned of the massive spill over the weekend through broadcasts on $\mathrm{CBS}, \mathrm{NBC}, \mathrm{ABC}$, and local news networks. 
Compared with the 2010 Deepwater Horizon oil spill, which instantly made news around the world due to the thousands of websites and blogs, Exxon had considerably more time to draft key response messages. BP had an hour, tops (K. Fearn-Banks, 2002). Due to the lack of 24/7 digital media during the time of the Valdez spill, Exxon was not held as accountable for certain actions as BP would have been. Frank Iarossi, then-president of Exxon Shipping and Exxon's main representative of the Valdez site, was left to initiate the crisis response, as Exxon CEO Lawrence Rawl, an employee at Exxon for 37 years, was missing in action. In contrast, BP CEO Tony Hayward was crucified by the public, even though he immediately made himself present at the spill site and available to the media and public. This highlights the extent of the evolution of crisis communications attributable to the Internet, new media, and especially social media (K. Fearn-Banks, 2002; R. Parekh \& E. Lee, 2010).

\subsection{Situational Crisis Communication Theory}

Since current study pertains to BP's use of crisis communications during the crisis response phase, the Situational Crisis Communication Theory serves as a guiding theoretical framework. SCCT is an attribution theory-based approach to crisis (R. Heath \& D. Miller, 2004). During the crisis response phase, a company or organization will attempt to protect its reputation by including specific response strategies within their communications tactics.

The main objective of SCCT is to develop a working system of strategies that can effectually protect an organization's reputation - or, at the very least, diminish the threat of having the organization's image tarnished (R. Heath \& D. Miller, 2004). SCCT was chosen as the foundation for the current study because it links attribution of responsibility with crisis type and because its main components include reputation repair strategies, crisis types, and attribution of responsibility.

Coombs outlined three phases of crisis management: pre-crisis, crisis response, and post crisis. The pre-crisis phase focuses on crisis prevention and preparation. The crisis response phase focuses on successfully responding to an occurring crisis. The post-crisis phase focuses on preparing for future crises while fulfilling promises made during the actual crisis. Pre-crisis best practices include having a continually updated crisis management plan, having a designated and properly trained crisis management team; implementing mock crisis exercises to test the reliability of the plan, and pre-drafting messages to combat specific crises. Postcrisis best practices include delivering all promised information to stakeholders, continually updating stakeholders on the progress of the crisis recovery efforts, and closely reviewing the crisis management actions to see if they should be integrated into future crisis management plans (Coombs, 2007).

\subsection{The role of $P R$ in crisis communication}

Grunig's Excellence Theory asserts that all communications must be strategically coordinated and executed by the public relations department. Granting management powers to this department empowers the company to successfully respond to a crisis, if and when one does occur (L. Hagan, 2007). The Federal Emergency Management Agency defines emergency management as "the managerial function charged with creating the framework within which communities reduce vulnerability to hazards and cope with disasters" (FEMA, 2007). Mitigation, when successfully executed, can drastically lessen the negative impact disasters may wreak on people and/or property. Examples of mitigation include purchasing flood insurance, enforcing building codes, or using fireretardant materials during construction.

Preparedness includes plans or procedures designed to save lives and minimize damage when an emergency occurs. Vital aspects of the preparedness phase include planning, training, and exercising disaster drills. Preparedness is a critical phase of emergency management because it ensures that crisis managers know what specific actions to take when a certain type of disaster occurs. Response involves the actions taken to save lives and prevent further damage in a disaster or emergency situation. Examples of responses include damage assessment, search and rescue, fire fighting, and sheltering victims. Recovery is action taken to return the community to normal following a disaster. Examples of recovery include repairing, replacing, or rebuilding property.

\subsection{Reputation repair strategies}

Just as important as the initial crisis response in the crisis response phase is that of reputation repair and behavioral intentions. Much research has been completed in order to compile a database of successful 
reputation repair strategies. Coombs' list of reputation repair strategies is often used by companies or organizations when a crisis occurs. This list includes nine strategies of reputation repair: attack the accuser, denial, scapegoat, excuse (provocation, defeasibility, accidental, or good intentions), justification, reminder, ingratiation, compensation, and apology (Coombs, 2007).

Attack the accuser exists when a crisis manager confronts the individual who is making a claim against the organization. Denial exists when a crisis manager denies the existence of a crisis. Scapegoat exists when a crisis manager places blame for the crisis on an individual outside of the organization. A provocation excuse exists when a crisis manager asserts that the crisis resulted out of a response to an outside individual's actions. A defeasibility excuse exists when a crisis manager claims to have had a deficient amount of information prior to the crisis.

An accidental excuse exists when a crisis manager had no control over events prior to the crisis. A good intentions excuse exists when a crisis manager insists that the organization meant to do good. Justification exists when a crisis manager attempts to minimize the resulting damage of the crisis. Reminder exists when a crisis manager reminds the organization's stakeholders of positive works that were completed by the organization in the past. Ingratiation exists when a crisis manager applauds the organization's stakeholders for specific actions. Compensation exists when a crisis manager offers a form of compensation, usually money, to victims of the crisis. Apology exists when a crisis manager apologizes for the crisis and takes full responsibility on behalf of the organization (Coombs, 2007).

Also present during the crisis response phase are the elements of crisis type and attribution of crisis responsibility, which typically go hand in hand. These elements are extremely important in determining the reputational threat of a crisis. There are three types of crises: victim crisis; accident crisis; and preventable crisis. A victim crisis may consist of a natural disaster, such as a hurricane or earthquake, a rumor, workplace violence, or product tampering. An accident crisis may consist of a challenge, technical error, or product harm. A preventable crisis may consist of a human-error accident, human-error product harm, or organizational misdeed. Usually, a victim crisis charges the organization with minimal crisis responsibility, an accident crisis charges an organization with low crisis responsibility, and a preventable crisis charges an organization with strong crisis responsibility.

\subsection{Research questions}

The purpose of this study is to better understand BP's use of Twitter as a crisis communication tool during the Gulf oil spill during the crisis response phase. By analyzing the content of BP's tweets during this time period, one may understand its public relations, crisis communications, and social media strategies. Specific topics that will be analyzed include: emergency management phases, reputation repair strategies, crisis types, attribution of responsibility, and Risk Smart items.

The following research questions about @BP_America's tweets guided this study:

RQ1: Which phase(s) of emergency management was the most prevalent?

RQ2: What reputation repair strategies were most prevalent?

RQ3: Which crisis types were reflected most often?

RQ4: Which type(s) of attribution of responsibility were reflected most often?

All corporate companies must have an online strategy to accompany a crisis communication plan, if they wish to be successful in the face of a crisis. This study examines how a lack of an online crisis communication plan, prior to a crisis, can prove detrimental to a company's reputation. It also highlights how social media networks such as Twitter can be used successfully as a crisis communication tool. Although a social media network may be used for many reasons during a crisis, this study examines how such a platform may be used for purposes pertaining to emergency management, reputation repair strategies, different crises, and different levels of responsibility attribution.

\section{Methods}

This study used a systematic, quantitative content analysis of all 1,161 tweets posted online by BP_America during its crisis response phase, April 20July 15, 2010. This period extended from the drilling rig explosion through the date the wellhead of the Macondo Prospect was capped. Tweets from April 20 
to June 4, 2010 and June 7-9, 2010 were obtained from http://topsy.com, a website that allows for real-time searches of the social web. In addition, tweets from June 5-6, 2010, and all remaining tweets (June 10-July $15,2010)$, were provided upon request by $\mathrm{BP}$ in the form of a spreadsheet titled "Twitter Content Log."

Coder A coded all tweets, while Coder B coded 20\% of the tweets (i.e. 232) by coding every fifth tweet of the sample. The 44-item code sheet identified concepts within each tweet. Items included the date in which the tweet was broadcast, actual text of the tweet, whether the tweet was an original post, retweet (RT), or @ reply, whether or not the tweet pertained to the Deepwater Horizon oil spill crisis, number of hashtags included in the tweet, terms used in hashtags, number of links included in the tweet, and where the link redirected the user.

The code sheet examined tweet content during different phase(s) of emergency management (mitigation, preparedness, response, and recovery), and strategies of reputation repair reflected in tweets (attack the accuser, denial, scapegoat, provocation excuse, defeasibility excuse, accidental excuse, good intentions excuse, justification, reminder, ingratiation, compensation, and/or apology). The study also identified crisis type(s) reflected in tweets (victim crisis, accident crisis, and preventable crisis), and type(s) of attribution of responsibility reflected in tweets (none, low/minimal, or a strong/high level of crisis responsibility).

The code sheet included items for month and date, and asked coders to record links that redirected the user to different websites. Coders identified whether each tweet was an original post, a retweet (RT), or a reply. An original post was defined as a tweet organically composed by BP_America. A retweet was defined as a tweet originally tweeted by another Twitter user that BP America chose to retweet, using its Twitter account. A retweet was identified by the "RT" abbreviation plus the other Twitter user's Twitter name (Ex: RT@johndoe13: see spot run...). A reply was defined as a tweet composed specifically in reply to another Twitter user or directed at a specific Twitter user. The reply was identified by the @ symbol at the beginning of a tweet, followed by the other Twitter user's Twitter name.

Each tweet was coded for whether it pertained to the Gulf of Mexico crisis, how many hashtags were included in the tweet, what term(s) were included in the hashtag, how many links were present within the tweet, and where the $\operatorname{link}(\mathrm{s})$ redirected the user. Coders then identified any of the four phases of emergency management (R.R. Dynes, E.L. Quarantelli \& G.A. Kreps, 1981) that were reflected in the tweet. The four phases of emergency management are mitigation, preparedness, response, and recovery. More than one phase could be present within a tweet.

A tweet in which mitigation was reflected would include language that attempted to reduce the impact of the Deepwater Horizon explosion and/or oil spill. Mitigation, the cornerstone of emergency management, is the continuing effort to lessen the impact that disasters have on people and property. Mitigation is sustained action that reduces or eliminates long-term risk to people and property from natural hazards and their effects.

If the word "mitigation," or a variation of that word, was included in the tweet, the coder chose this crisis phase. A tweet in which preparedness was reflected would include language that revealed the existence and/or development of risk management plan(s) for the current and/or future oil spill(s), such as training, drills, plans or procedures designed to save lives or to minimize damage when an emergency occurs. A tweet in which response was reflected would include mentions of oil spill emergency services, such as actions taken to save lives or prevent further damage in a disaster or emergency situation. Response is putting preparedness plans into action (R.R. Dynes, E.L. Quarantelli \& G.A. Kreps, 1981). This phase also includes protecting wildlife and/or shorelines by way of booms, dispersants, and skimming.

A tweet in which recovery was reflected would include mentions of oil spill recovery efforts to rebuild and repair damage caused by the explosion or oil spill. Recovery efforts may include mentions of repair, replacement, rebuilding, cleanup, drilling of relief wells, capping of the well, etc. Recovery includes monetary response efforts, such as donations from BP, fines assigned to BP, personal claims, etc., or other actions taken to return the community to normal.

Reputation repair strategies were coded in terms of whether the tweet:

(i) Confronted a person or group claiming that something is wrong with BP 
(ii) Asserted that no crisis, or specific aspect of the crisis, is present

(iii)Placed blame of the crisis on an outside group or person

(iv)Attempted to make an excuse by claiming the crisis was a result of someone else's actions

(v)Attempted to make an excuse by claiming a lack of information about events leading up to the explosion or oil spill

(vi)Attempted to make an excuse by claiming a lack of control over events leading up to the explosion or oil spill

(vii)Attempted to make an excuse by claiming that the organization meant to do well

(viii)Included a justification that minimizes the perceived damage caused by the explosion or oil spill (ix)Reminded people of past good works completed by BP

(x)Reminded people of a specific amount of oil collected, money paid in claims, boom deployed in response to the oil, or wildlife rescued

(xi)Praised BP stakeholders for their actions pertaining to the oil spill, including the thanking or praising of volunteers

(xii)Included offers of money or other gifts from BP to direct and indirect victims of the explosion or oil spill such as claims given to individuals, research funds, or wildlife funds

(xiii)Indicated that BP accepted full responsibility for the explosion or oil spill or asked stakeholders for forgiveness.

Coders recorded whether the tweet reflected a victim, accident, or preventable crisis. Only one crisis type could be chosen per tweet. A tweet in which victim crisis was reflected would claim that BP was the victim of the explosion or oil spill, such as the victim of the crisis was a result of a natural disaster, rumor, or product tampering/malevolence (ex: the oil spill being compared to Hurricane Katrina). A tweet in which an accident crisis was reflected would claim that the explosion or oil spill was an accident. An accident crisis could include a challenge, such as a stakeholder claiming the organization operated in an inappropriate manner, a technical error accident such as the explosion and/or oil spill being caused by equipment or technology failure, or technical error product harm such as an equipment or technology failure caused a product to be defective or harmful.
A tweet in which a preventable crisis was reflected would claim that the explosion or oil spill could have been prevented. For example, the crisis may have been caused by a human-error accident (i.e. the explosion and/or oil spill was caused by human error), human-error product harm (i.e. a product was defective or harmful because of a human error), or organizational misdeed (i.e. BP management actions put stakeholders at risk and/or violated the law).

Coders evaluated three types of attribution of responsibility reflected in the tweets: no crisis responsibility, low or minimal crisis responsibility, and strong or high crisis responsibility. Only one type of attribution of responsibility was coded for each tweet. A tweet in which no crisis responsibility was reflected would indicate that BP was not responsible for the explosion or oil spill or that the explosion or oil spill was a victim crisis, such as Hurricane Katrina.

A tweet in which low/minimal crisis responsibility was reflected would indicate that BP was minimally responsible for the explosion or oil spill. This type of attribution of responsibility indicated that the explosion or oil spill was an accident crisis. For low/minimal crisis responsibility, no specific actions taken by BP were noted. However, if BP tweeted about an entity separate from itself taking an action against the oil spill, this would reflect low/minimal crisis responsibility. A tweet in which strong/high crisis responsibility was reflected indicated that BP took full responsibility for the explosion and/or oil spill. For strong/high crisis responsibility tweets, a specific action was noted when one was mentioned.

During the initial coding process, recurring themes present in the hashtag term(s) and link redirection site(s) were noted, and a secondary coding process was implemented to quantify recurring hashtag terms and URLs. Recurrent and/or unique hashtag terms and URLs were then given a label and were included in the spreadsheet so they could be accounted for as well. Because of the approach used, the hashtag term and URL coding was not exhaustive. The following hashtags were included in the spreadsheet: \#bp, \#oilspill, \#Oil_Spill_2010, \#gulf, \#air, \#water, \#birds, \#topkill, \#bpcares, \#uscg, and \#usfws. 


\section{Findings}

The greatest proportion of BP's tweets (40\%) appeared in the last two weeks of the crisis response phase, while only 0.3 percent of the tweets appeared in the first two weeks. About $23 \%$ appeared in May, and 37\% appeared in June. About $85 \%$ of all BP tweets were original posts, while only eight percent were replies and six percent were retweets. Out of all tweets, 99.5\% were relevant to the oil spill. A total of 572 hashtags appeared within the tweets; 129 tweets included a single hashtag; 200 tweets (18 percent) included two hashtags; 13 tweets included three hashtags; and one tweet included four hashtags. A total of 815 links were included within the tweets; 763 tweets included one link, 20 tweets included two tweets, and four tweets included three links.

URLs directed the user from BP's tweets to BP's website (general); BP's Press page on website; BP's Gulf of Mexico restoration page on website; Facebook; YouTube; Flickr; RestoreTheGulf.gov; Deepwater Horizon Memorial; ABC; CNN; CSPAN; CBS; NPR; AP; PBS; MSNBC; The Wall Street Journal; The New York Times; The Los Angeles Times; The Huffington Post; The Boston Globe; USA Today; U.S. Coast Guard; GeoPlatform.gov/GulfResponse; U.S. Environmental Protection Agency; Tri-State Bird Rescue; U.S. Fish and Wildlife Service; International Bird Rescue; National Fish and Wildlife Foundation; National Oceanic and Atmospheric Administration.
RQ1 examined which phases of emergency management were most prevalent in BP's tweets. The four phases were reflected in the 1,161 tweets on 1,090 separate occasions. Of the four phases of emergency management (mitigation, preparedness, response, recovery), the recovery phase was most prevalent in tweets from BP, appearing in $54 \%$ of the tweets. The response phase appeared in $36 \%$ of the tweets, while the preparedness phase appeared in three percent of the tweets, and the mitigation phase appeared in only $0.4 \%$ of the tweets.

Over the 13-week time period, the response phase surfaced most often in tweets during week 12, when BP's final attempts to sealed the leak were going well and it saw a rise in shares for the first time since the explosion. The fewest response tweets appeared in the second week of the crisis, when the government investigation began, state emergencies were declared, and the rate of oil flow was declared to be far worse than originally thought. The recovery phase surfaced most in tweets during the last week of the crisis, when BP stopped the oil leak for first time since the explosion (Figure One). Meanwhile, weeks three and seven had the fewest tweets that referenced recovery. During week three, BP blamed Transocean for the oil spill, and during week seven, BP faced political flack over its decision to pay out more than $\$ 10$ billion in dividends to its shareholders rather than to victims.

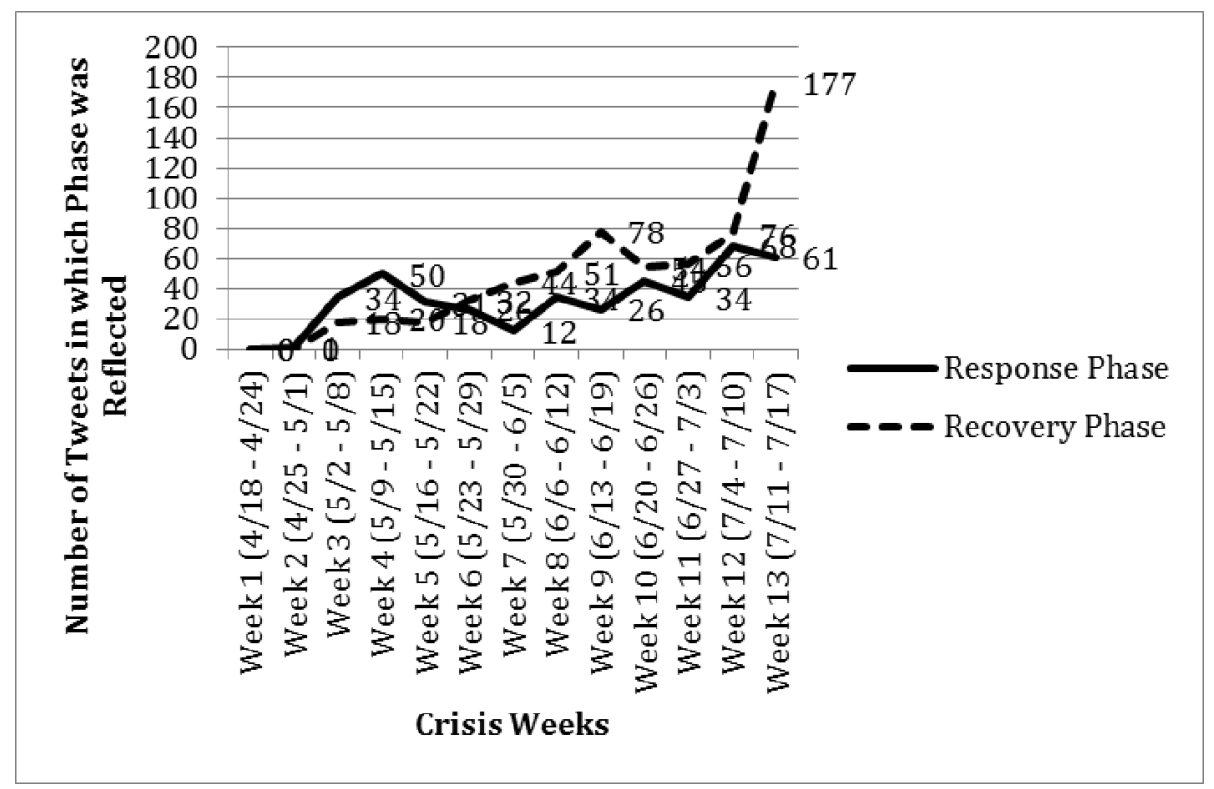

Fig. 1. Response vs. Recovery in Post-Spill Tweets

Published by Atlantis Press

Copyright: the authors 
RQ2 examined which reputation repair strategies were most prevalent in tweets (Table 1). These reputation repair strategies included attack the accuser, denial, scapegoat, excuse through provocation, excuse of defeasibility, excuse about an accidental situation, excuse from good intentions, justification, reminder, ingratiation, compensation, and apology. Of these 12 reputation repair strategies, eight were reflected within the tweets: compensation (14\%), reminder $(12 \%)$, denial $(0.9 \%)$, ingratiation $(0.5 \%)$, apology $(0.5 \%)$, justification $(0.3 \%)$, attack the accuser $(0.1 \%)$, and accidental excuse $(0.1 \%)$. None of the tweets reflected the scapegoat, excuse (provocation), excuse (defeasibility), and excuse (good intentions) strategies.

Table 1. Reputation Repair Strategies in BP Tweets

\begin{tabular}{lrr}
\hline Strategies & Frequency & Percent \\
\hline Compensation & 163 & $14.0 \%$ \\
Reminder & 139 & $12.0 \%$ \\
Denial & 11 & $0.9 \%$ \\
Ingratiation & 6 & $0.5 \%$ \\
Apology & 6 & $0.5 \%$ \\
Justification & 4 & $0.3 \%$ \\
Attack the accuser & 1 & $0.1 \%$ \\
Excuse (accidental) & 1 & $0.1 \%$ \\
Scapegoat & 0 & $0.0 \%$ \\
Excuse (provocation) & 0 & $0.0 \%$ \\
Excuse (defeasibility) & 0 & $0.0 \%$ \\
Excuse (good intentions) & 0 & $0.0 \%$ \\
\hline
\end{tabular}

Reminder and compensation strategies of reputation repair were most prevalent (Figure Two). Reminder tweets appeared most frequently during week 10, when BP shares hit a 14-year low, and least often during weeks three and four, when BP blamed Transocean for the crisis. Compensation tweets appeared most often in week nine, when the White House demanded that BP pay $\$ 20$ billion in compensation to victims and no dividends to shareholders. Compensation was mentioned least often during week 6 , when the U.S. launched a criminal investigation into the oil spill.

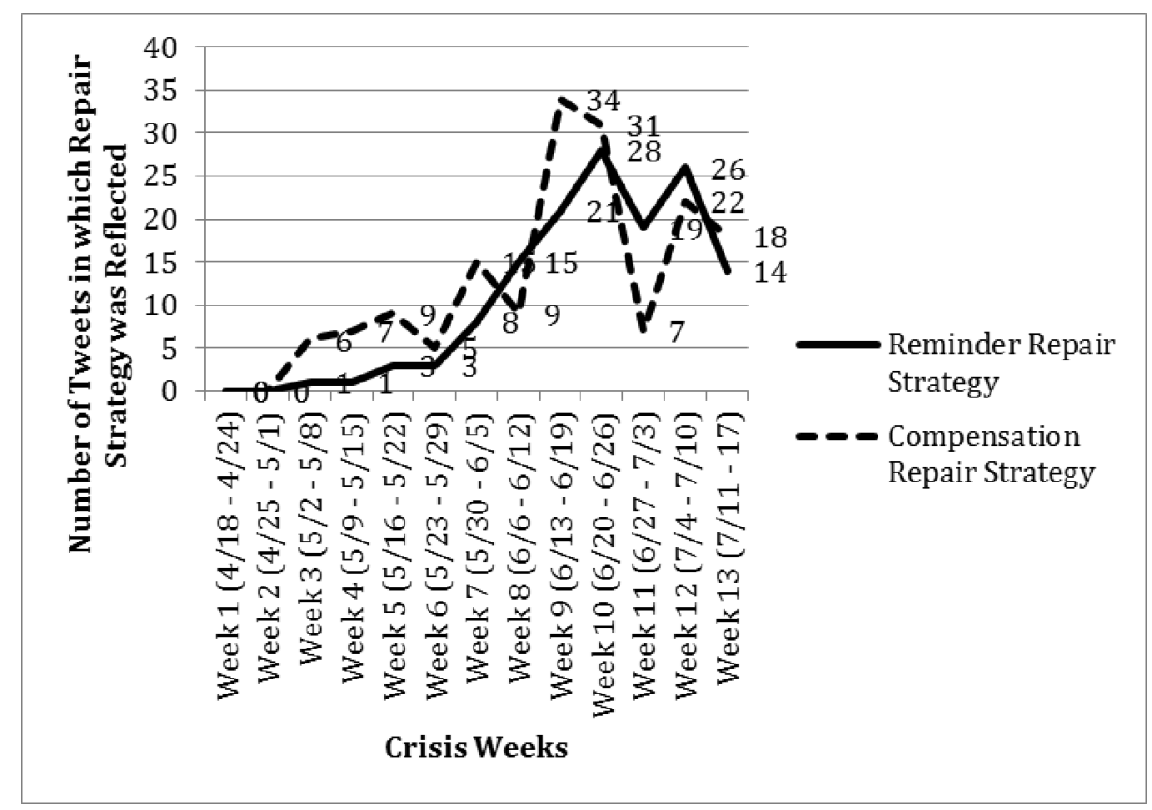

Fig. 2. Reminder vs. Compensation Strategies in BP Tweets 
RQ3 identified which of the three crisis types (victim, accident, preventable) were reflected most often in tweets. Accident crisis was reflected most often, appearing in $97 \%$ of tweets, while victim crisis was reflected in only $0.2 \%$ and preventable crisis in $0.1 \%$. Preventable crisis was reflected in only one tweet $(0.1 \%)$.

RQ4 examined which responsibility attribution types were reflected most frequently. The three types were no crisis responsibility, low/minimal crisis responsibility, and strong/high crisis responsibility. The strong/high crisis responsibility type was reflected most often, appearing in $90 \%$ of all tweets. Low $/$ minimal crisis responsibility was reflected in only seven percent, while no crisis responsibility was reflected in $0.2 \%$ of the tweets.

Among tweets reflecting that the oil spill "had strong political attributes tied to it," most were tweeted during week nine, when Congress accused BP's CEO of "stonewalling" after failing to answer questions about the spill's causes. The fewest were tweeted in the following week, week nine, when the BP CEO failed to appear at a gathering of the oil industry and Greenpeace protesters stormed the stage at the convention.

Most tweets reflecting that the oil spill "caused serious financial harm" appeared in week nine, when BP's credit rating was downgraded by Moody's after expressing concern at the escalating cost of the cleanup and potential cost of litigation claims. The fewest were tweeted during week 6 , when BP began an advertising campaign in the U.S. aimed at boosting opinion. Among tweets reflecting that the oil spill "caused death/injury through action or inaction," most appeared during week ten, when hundreds of activists staged protests against BP in London. The fewest of these tweets appeared during weeks two, when catastrophic contamination and wildlife destruction was reported, and in week six, when the U.S. launched a criminal investigation into the oil spill.

All tweets were coded for the following hashtags: \#bp; \#oilspill; \#Oil_Spill_2010; \#gulf; \#air; \#water; birds; \#topkill; \#bpcares; \#uscg; \#usfws. The most prevalent hashtag was \#oilspill, which appeared in $26 \%$, followed by \#bp, which appeared in $19 \%$. \#Oil_Spill_2010 appeared in only 0.5\%, \#topkill and \#usfws each appeared in $0.3 \%$. \#gulf and \#uscg appeared in $0.3 \%$, and \#air, \#water, \#birds, and \#bpcares appeared in $0.1 \%$.

BP seldom used redirects in its tweets (Table Two). URLs redirected users to RestoreTheGulf.gov in ten percent of the tweets, followed by the Gulf of Mexico restoration page on BP's website (nine percent), YouTube (eight percent), and BP's general website (eight percent). URLs redirected users to the Press page on BP's website on 77 occasions (seven percent). URLs redirected users to Facebook on 57 occasions (five percent).

URLs redirected users to CNN on 46 occasions (four percent). URLS redirected users to Flickr and CSPAN on 19 occasions, respectively (two percent). URLs redirected users to the U.S. Environmental Protection Agency on 14 occasions (1\%). URLs redirected users to MSNBC on 12 occasions (one percent). URLs redirected users to GeoPlatform.gov/GulfResponse on 11 occasions (one percent). URLs redirected users to $A B C$ on nine occasions (one percent). URLs redirected users to the National Oceanic and Atmospheric Administration on eight occasions (one percent). URLs redirected users to the AP and Tri-State Bird Rescue on five occasions, respectively $(0.4 \%)$. URLs redirected users to CBS and the U.S. Coast Guard on four occasions, respectively $(0.3 \%)$.

BP seldom redirected users to news media outlets. URLs redirected users to the Wall Street Journal, New York Times, Los Angeles Times, NPR, PBS, the Boston Globe, but only about two mentions for each of these media outlets $(0.4 \%$ across all tweets). Even less frequently, URLs redirected users to Huffington Post or USA Today $(0.1 \%)$.

\section{Discussion}

This study evaluated BP's use of Twitter as a crisis communication tool during the 2010 Deepwater Horizon crisis response phase. The research questions guided an analysis of the emergency management phases, reputation repair strategies, crisis types, and types of attribution of responsibility within BP's tweets posted April 15-July 15, 2010.

The recovery phase of emergency management was most prevalent, reflected in $54 \%$ of the tweets. BP used most of its tweets during the recovery phase to inform 
its audience of its efforts to rebuild or repair damages in the Gulf and on the coast, particularly the repair or rebuilding of the damaged Macondo well. These efforts included the Lower Marine Riser Package, the Riser Insertion Tube Tool, and drilling relief wells.

Table 2. Website Redirects within BP Tweets

\begin{tabular}{lcc}
\hline Websites & Frequency & Percent \\
\hline Webpage on BP Corporate Site & 273 & $23.4 \%$ \\
Social Media & 169 & $14.5 \%$ \\
Government Oil Spill Response & 124 & $10.6 \%$ \\
National Broadcast & 101 & $8.5 \%$ \\
Government Agency & 27 & $2.3 \%$ \\
Elite Newspaper & 13 & $1.0 \%$ \\
Environmental Agency & 8 & $0.7 \%$ \\
Other & 1 & $0.1 \%$ \\
\hline
\end{tabular}

Recovery tweets also included information about coastal cleanup efforts and wildlife rehabilitation and release. The response phase was the second-most prevalent emergency management phase seen during this period, appearing within $36.3 \%$ of the tweets. This means that BP also used a large number of tweets to provide information about saving wildlife and preventing further damages. Response tweets included information about rescuing wildlife and protecting shorelines from oil using booms, dispersants, and skimming. Response tweets were most prevalent during the early weeks of the crisis response, and they gradually decreased over time. The opposite is true of recovery tweets, which increased over time. This shows that BP acted in way that was directly in line with emergency management protocol. That cycle begins with mitigation, moves into preparedness, then response, then recover, and back to mitigation.

Among the reputation repair strategies reflected in tweets, the compensation and reminder strategies appeared at a much higher rate than the other ten strategies. The compensation strategy appeared in $14 \%$ of the tweets, revealing that BP only occasionally provided information about claims given to individuals who were financially harmed as a direct result of the oil spill or about donations made to research and wildlife funds.

The reminder strategy appeared in $12 \%$ of the tweets, indicating the extent that BP provided reminders of good works pertaining to the oil spill that had been completed. These good works included individual claims checks cut, money donated to research or wildlife funds, amount of oil collected, and amount of boom deployed. During the ninth week, the most compensation tweets appeared, in the same week that BP announced its agreement to pay \$20 billion over 3.5 years to meet the obligations arising from the oil spill. Week ten contained the most reminder tweets; the same week that BP announced it would donate the net revenue from the sale of oil recovered from the Macondo well to the National Fish and Wildlife Foundation. They immediately donated $\$ 5$ million.

The accident crisis type was reflected most often, appearing in $97 \%$ of tweets. An overwhelming majority of tweets during the analyzed 13-week crisis response period suggested that the explosion and/or oil spill was an accident. Most tweets during this period suggested an accident crisis, since the investigation into the cause of the explosion and oil spill had not found BP responsible. Ongoing investigations never proved that BP was guilty of a human-error accident, humanerror product harm, or an organizational misdeed.

A strong/high level of crisis responsibility was most often reflected within tweets, appearing in $90 \%$ of all tweets. This means that an overwhelming majority of tweets during the analyzed 13-week crisis period indicated that BP took full responsibility for the explosion, oil spill, and all resulting issues. Since Admiral Thad Allen, a retired U.S. Coast Guard admiral, was appointed as National Incident Commander of the Unified Command for the Deepwater Horizon oil spill, his name was mentioned in a large amount of tweets, implying strong political attributes.

BP included hashtags in many tweets in an attempt to be included in trending conversations in the twitterverse. Although a variety of hashtag terms were used during the crisis response phase, \#oilspill 
and \#bp were by far used the most. This is probably because these terms were more popular trending terms; therefore, if BP used these specific hashtag terms, they were able to secure a place in trending conversations. Hashtags that did not trend well they immediately retired. For example, the hashtag \#bpcares appeared in only one tweet during the analyzed 13-week period.

BP strategically included certain links in its tweets, as well. Most links either redirected users to RestoreTheGulf.gov, a government website created solely for the Gulf oil spill, BP's website, or to one of BP's other social media outlets. BP probably redirected users most to the government website to gain or retain the trust of its followers, while it probably redirected users to its other websites to remain the main source of information relating to the oil spill.

After the explosion of the Deepwater Horizon drilling rig and the resulting Gulf oil spill, BP implemented an extensive online crisis communication and public relations campaign. One major leg of this campaign consisted of repurposing its Twitter account, @ BP_America, to serve as a hub for updates and information pertaining to the oil spill response. @ BP_America tweeted its first oil spill-related tweet on April 27, seven days after the explosion, and continued to tweet thousands of oil spill-related tweets as the response and recovery efforts continued.

BP used its Twitter account for a variety of reasons, and quite strategically. The tweets reflected various emergency management phases, reputation repair strategies, crisis types, types of attribution of responsibility, and public perceptions. BP implemented specific reputation repair strategies in a manner in response to current events. For example, BP employed a compensation strategy after making a large monetary donation or a reminder strategy after collecting a large amount of oil.

One area of BP's crisis communication plan was not in line with past crisis communication research. Coombs' Situational Crisis Communication Theory suggests that accident crisis types usually indicate a low or minimal attribution of responsibility. However, most of BP's tweets revealed an accident crisis with a high or strong attribution of responsibility. Although the investigation into the explosion and oil spill did not point to a preventable crisis, BP still took full responsibility for the incident. Also, preventable crisis was only reflected in one tweet, as ongoing investigations during the crisis response period never proved that BP was responsible for a human-error accident, human-error product harm, or organizational misdeed.

Although BP provided a Twitter Content Log for most tweets analyzed in this content analysis, this log only dated back to June 5,2010 , so missing tweets from June 6-9 were obtained through Topsy.com, a credible search engine with an extensive Twitter library. However, there is always the possibility that some tweets from@BP_America might be missing from its library.

BP extensive online crisis communication campaign included the use of online sites other than Twitter, including its corporate website, Facebook, Flickr, and YouTube. Future research might study how BP used all social media outlets across all crisis phases of the oil spill, in light of reputation repair strategies and public perceptions. One could then compare the use of these social media outlets to Twitter and uncover important similarities and differences. Finally, future research might compare BP's Twitter response to tweets used in a different corporate crisis, such as the 2010 Toyota recall for brake problems, to examine how they responded differently in admitting mistakes to the public.

\section{References}

M. DeBord, Crisis PR must not confront its own problems, The Washington Post (July 25, 2010).

J. Vidal, BP's PR campaign fails to clean up reputation after Gulf oil spill, Guardian, 2011.

http://www.guardian.co.uk/environment/blog/2011/apr/14 /bp-pr-campaign-gulf-oil-spill

R. Blake, "BP Shares Sink Amid Oil Spill Bankruptcy Chatter." ABC News (June 10, 2010).

http://abcnews.go.com/Business/bp-survive-companyresult-oil-spill-gulf-mexico/story?id=10874702

Associated Press, "BP chief at yacht race while oil spews into Gulf," New Zealand Herald (June 20, 2010).

E. Reguly, BP's PR woes start at the top, The Globe and Mail (June 16, 2010).

E. McClam and H. Weber, BP's failures made worse by PR mistakes, MSNBC.com, 2010.

D. Lenci and J. Mullane, Communicating with the public: How BP told the Macondo story, Oil \& Gas Journal (December 6, 2010).

A. Brownsell, BP, Marketing (July 2010).

B. Snyder, Tony Hayward's greatest hits, CNN Money, June 10, 2010.

http://money.cnn.com/2010/06/10/news/companies/tony_ hayward_quotes.fortune/index.htm 
A. Caruba, BP, PR, and the Oil Spill, Canada Free Press (June 7, 2010).

D. Lenci, Denise and J. Mullane, Communicating with the public: How BP told the Macondo story, Oil \& Gas Journal (December 6, 2010).

T. Bergin, "Analysis: BP PR blunders carry high political cost." Reuters (June 29, 2010).

A. Symington, Legacy of the BP spill: What's a reputation worth? The BP spill in the Gulf of Mexico caused a public outcry and savaged BP's share price. Image repair won't be easy, Christian Science Monitor (October 18, 2010).

B. Morrissey, BP gets aggressive, Adweek (June 21, 2010).

A. Seitz-Wald, 'BP Launches 'Aggressive' Social Media Campaign but Disables Comments from Users Who Don't 'Like' It," Truth-out.org (June 11, 2010). http://www.truth-out.org/bp-launches-aggressive-socialmedia-campaign-disables-comments-users-who-dontlike-it60633

B. Hatton, BP's PR crisis shows why social media matters, Daily Post (August 2, 2010).

H. Shaw, The truth shall set you free of PR hell, National Post (June 25, 2010).

K. Fearn-Banks, Crisis Communications: A Casebook Approach (Mahwah, NJ: Lawrence Erlbaum, 2002), p. 8.

T. Coombs, Crisis Management and Communications, Gainesville, FL: Institute for Public Relations, 2007: http://www.instituteforpr.org/topics/crisis-managementand-communications/

R. Parekh and E. Lee. "How to Succeed when it's Time to Make Your Social-Media Mea Culpa." Advertising Age 81 (19): 2, 2010.

R. L. Heath and D. P. Miller, Responding to a Crisis: A Rhetorical Approach to Crisis Communication (Mahwah, NJ: Lawrence Erlbaum, 2004), p. 97.

L. M. Hagan, "For reputation's sake: Managing crisis communication," in The Future of Excellence in Public Relations and Communications Management, ed. E. L. Toth (Mahwah, NJ: Lawrence Erlbaum, 2007), p. 413.

FEMA, Principles of Emergency Management Supplement (Sept. 11, 2007), p. 4.

R. R. Dynes, E. L. Quarantelli, and G. A. Kreps, Report Series \#11, A Perspective on Disaster Planning, 3rd ed., Newark, DE: University of Delaware Disaster Research Center, 1981. 